\title{
Malnutrition in Non-Hodgkin Lymphoma Patients at Dr. Hasan Sadikin General Hospital Bandung
}

\author{
Azizah Puspitasari Ardinal, ${ }^{1}$ Siska Wiramihardja, ${ }^{2}$ Indra Wijaya ${ }^{3}$ \\ ${ }^{1}$ Faculty of Medicine Universitas Padjadjaran, Indonesia, ${ }^{2}$ Department of Public Health Faculty \\ of Medicine Universitas Padjadjaran, Indonesia, ${ }^{3}$ Department of Internal Medicine Faculty of \\ Medicine Universitas Padjadjaran/Dr. Hasan Sadikin General Hospital Bandung, Indonesia
}

\section{Abstract}

Background: Non-hodgkin lymphoma (NHL) has the highest prevalence among hematologic malignancies. The prognosis and response to therapy in NHL patients may worsen in the presence of malnutrition. The aim of the study was to describe the malnutrition status in NHL patients.

Methods: This was a cross-sectional descriptive study. Nutritional status was assessed using Subjective Global Assessment (SGA) obtained from the medical records of all NHL patients at Dr. Hasan Sadikin General Hospital registered in 2017.

Results: In total, there were 78 medical records of NHL patients that fulfilled the inclusion criteria. All NHL patients had experienced malnutrition, categorized as mild-moderate malnutrition (70.5\%) and severe malnutrition (29.5\%). In NHL patients with mild-moderate malnutrition, 29\% had 5-10\% weight loss; $60 \%$ had suboptimal solid diet; $56.4 \%$ experienced anorexia; and $50.9 \%$ had subcutaneous fat loss. In NHL patients with severe malnutrition, $78.3 \%$ had more than $10 \%$ weight loss; $73.9 \%$ had suboptimal solid diet; $78.3 \%$ experienced anorexia; and 100\% had subcutaneous fat loss.

Conclusions: Based on subjective assessment, all NHL patients were malnourished and experienced change of food intake and loss of subcutaneous fat, therefore, a better nutritional support scheme are crucial for NHL patients.

Keywords: Non-hodgkin lymphoma, malnutrition, subjective global assessment

\section{Introduction}

Non-hodgkin lymphoma (NHL) is a malignancy derived primarily from lymphocytes, mostly from $B$ and T cells. ${ }^{1}$ The prevalence of NHL is the highest among all hematologic malignancies with the incidence is $2.8 \%$ among all cancers. In Indonesia, NHL is the seventh most frequently diagnosed cases among all cancers with $4.1 \%$ incidence. Malnutrition in cancer patients is usually caused by chronic inflammation. But in hematological malignancies, the high dose of chemotherapy may worsen the nutritional status. NHL patients' nutritional status may affect the patients' respond to therapy and prognosis. $^{2}$

There are several screening tools available to be used as a nutritional assessment in cancer patients. Previous studies had shown various malnutrition among cancer patients, for example NRS 2002 has been used as the screening tool and it is common among oncology patients to have a higher risk of malnutrition. ${ }^{3}$ Another study has used NRI as screening tools, resulted that around $40 \%$ of cancer patients were malnourished. ${ }^{4}$ Recently, American Society for Parenteral and Enteral Nutrition (ASPEN) recommends Subjective Global Assessment (SGA) as a nutritional screening tool. ${ }^{5}$ A study conducted in China has shown that the clinical application of SGA in gastrointestinal cancer is a safe, cheap, and reliable method to screen patients' nutritional status. ${ }^{6}$

Nutrition is an important aspect in cancer patients. Study about nutritional status of cancer patients has been conducted in Medan, ${ }^{7}$

Correspondence: Azizah Puspitasari Ardinal, Faculty of Medicine, Universitas Padjadjaran, Jalan Raya BandungSumedang Km.21, Jatinangor, Sumedang, Indonesia, Email: azizahardinal40@gmail.com 
however, SGA as a tool in assessing nutritional status among NHL patients has not been explored. The aim of the study was to describe the nutrition status among NHL patients at Dr. Hasan Sadikin General Hospital, registered in 2017.

\section{Methods}

This study was a descriptive cross-sectional study. Study protocol had been approved by the Health Research Ethics Committee, Faculty of Medicine, Universitas Padjadjaran number 376/UN6.KEP/EC/2018. Data were collected from the medical records of all NHL patients registered in 2017. The inclusion criteria were NHL patients aged 18 years old or older. Incomplete medical records were excluded.

Nutritional status of the patients were obtained from the SGA form that were included in the patients medical record. Generally, SGA has been considered as gold standard to detect malnutrition as recommended by American Society for Parenteal and Enteral Nutrition (ASPEN). Points assessed by SGA were recent weight loss, gastrointestinal changes (nausea, vomit, diarrheae, anorexia), changes in functional capacity, and physical changes (muscle atrophy, subcutaneous fat loss, edema and ascites). SGA was then categorized into SGA-A, SGA-B, and SGA-C for well-nourished, mild to moderately malnourished, and severely malnourished, respectively. SGA-A was designated when the patient had no weight loss, no gastrointestinal symptoms, no change of food intake, no subcutaneous fat loss, no muscle wasting, and no ankle edema; SGA-B when the patient had marked changes in food intake and 5-10\% weight loss with mild to moderate condition in other variables; SGA-C when the patient had severe change of food intake or starvation, more than $10 \%$ weight loss, and severe condition in other variables. ${ }^{6}$ The data was analyzed using IBM SPSS Statistic version 22.0.

\section{Results}

Out of 116 NHL adult patients registered during 2017, complete data were collected from 78 patients. All patients were malnourished; $70.5 \%$ had mild-moderate malnutrition and $29.5 \%$ had severe malnutrition. Due to the significant differences in the number of patients among the two groups, this study only described the characteristics within each group.
The patients' characteristic showed that most of the malnourished patients in both degree of malnutrition were males. The age group that had the highest incidence was 61 to 70 years old $(25.5 \%)$ in mild-moderate malnutrition and 51 to 60 years old $(30.4 \%)$ in severe malnutrition. The majority of patients with mild-moderate malnutrition (50.9\%) and severe malnutrition (56.5\%) were senior high school graduates. More than half of patients with mild-moderate malnutrition was still ambulatory (65.5\%). Meanwhile in patients with severe malnutrition, the number of patients who was immobile was slightly higher than those who were not (52.2\%). Nearly half of patients with mild-moderate malnutrition had normal BMI (49.1\%). Almost all severely malnourished patients were underweight according to the BMI (91.3\%) (Table 1).

Weight loss in patients with mild-moderate malnutrition were varied with most frequent loss between 5-10\% (29.1\%). Most of patients with severe malnutrition experienced more than $10 \%$ weight loss $(78.3 \%)$. Suboptimal solid diet was the most common form of dietary intake change in both degree of malnutrition (60\% and $73.9 \%)$. While the most common type of gastrointestinal change experienced by patients from both degree of malnutrition was anorexia ( $56.4 \%$ and $78.3 \%$ ). Half of the patients with mild-moderate malnutrition $(50.9 \%)$ and all of the patients with severe malnutrition (100\%) experienced subcutaneous fat loss (Table 2).

\section{Discussion}

Our study has shown that all NHL patients experienced malnutrition with mild-moderate malnutrition in larger proportion compared to severe malnutrition. This finding is consistent in other study showing that NHL patients had more mild-moderate malnutrition than severe malnutrition. ${ }^{7}$ Malnutrition is the most often comorbidity found in cancer patients, known as chronic disease-related malnutrition. ${ }^{8}$ The protein, carbohydrate, and fat metabolism are all affected by chronic systemic inflammation due to the presence of malignancy which causes a hyper catabolic condition. ${ }^{9}$

There are more malnourished patients detected by SGA than BMI in this study. Nutritional status could not be concluded by the measurement of current anthropometry only. It is important to consider the use of screening tools that assess other factors such as weight loss, anorexia, muscle atrophy, and subcutaneous fat loss. This finding is 
Table 1 Characteristics of Non Hodkin Lymphoma (NHL) Patients and Nutritional Status According to Subjective Global Assessment

\begin{tabular}{lcc}
\hline & \multicolumn{2}{c}{ Malnutrition } \\
\cline { 2 - 3 } & $\mathrm{n}(\%)$ & $\begin{array}{c}\text { Mevere (SGA-C) } \\
\mathrm{n}(\%)\end{array}$ \\
\hline Gender & $32(58.2)$ & $15(65.2)$ \\
Male & $23(41.8)$ & $8(34.8)$ \\
Female & & \\
Age (years) & $6(10.9)$ & $5(21.7)$ \\
$18-30$ & $12(21.8)$ & $3(13)$ \\
$31-40$ & $11(20)$ & $3(13)$ \\
$41-50$ & $9(16.4)$ & $7(30.4)$ \\
$51-60$ & $14(25.5)$ & $4(17.4)$ \\
$61-70$ & $3(5.5)$ & $1(4.3)$ \\
$\geq 71$ & & $1(4.3)$ \\
Education level & $2(3.6)$ & $2(8.7)$ \\
Not finished elementary school & $10(18.2)$ & $6(26.1)$ \\
Elementary school & $5(9.1)$ & $13(56.5)$ \\
Junior high school & $28(50.9)$ & $1(4.3)$ \\
Senior high school & $10(18.2)$ & \\
Bachelor & & $21(91.3)$ \\
Body mass index (kg/m2) & $16(29.1)$ & $1(4.3)$ \\
$<18.5$ & $27(49.1)$ & - \\
$18.5-22.9$ & $5(9.1)$ & \\
$23-24.9$ & $7(12.7)$ & \\
$\geq 25$ & & \\
& & \\
\hline
\end{tabular}

consistent, showing that malnutrition is more identified by SGA rather than than BMI. ${ }^{6}$ Interestingly, nearly half of the mild to moderately malnourished patient have normal BMI. Moreover, male has experienced mild-moderate malnutrition and severe malnutrition. This finding might be due to the higher incidence of NHL in male population than female population in Indonesia ${ }^{2}$ and this similar result has been showed that there is higher incidence of malnutrition in male population. ${ }^{7}$

The incidence of malnutrition among patients' age group in this study is equally distributed. This finding is not in accordance with the study, resulting that the risk of malnutrition in hospitalized oncology patients is increased in elderly. ${ }^{3}$ However, age is not the only factor that contributes to the incidence of malnutrition. The other factors that may be related to malnutrition are among others smoking, reduced functional capacity, and low socio-economic status. ${ }^{10}$

Furthermore, anorexia is the most common form of gastrointestinal changes that is experienced by NHL patients in this study (62.8\%). This condition decreases patients' food intake that may cause nutrient deficiencies. This finding is in corcordance with the fact that anorexia is the most common cause of decreased food intake in cancer patients $(62.5 \%){ }^{4}$ The occurrence of anorexia in cancer patients might be due to chronic inflammation which releases some cytokines, affecting the appetite regulator in the hypothalamus are TNF- $\alpha$ and IL-6. TNF- $\alpha$ may also increase gluconeogenesis, lipolysis, and proteolysis. Serotonin release from 
Table 2 Nutritional characteristics of Non Hodkin Lymphoma (NHL) Patients According to Subjective Global Assessment

\begin{tabular}{|c|c|c|}
\hline & \multicolumn{2}{|c|}{ Malnutrition } \\
\hline & Mild-moderate (SGA-B) & Severe (SGA-C) \\
\hline & $\mathrm{n}(\%)$ & n (\%) \\
\hline \multicolumn{3}{|l|}{ Weight loss } \\
\hline No & $14(25.5)$ & $1(4.3)$ \\
\hline \multicolumn{3}{|l|}{ Yes } \\
\hline $0-5 \%$ & $13(23.6)$ & $2(8.7)$ \\
\hline $5-10 \%$ & $16(29.1)$ & $2(8.7)$ \\
\hline$>10 \%$ & $12(21.8)$ & $18(78.3)$ \\
\hline \multicolumn{3}{|l|}{ Intake changes } \\
\hline No & $11(20)$ & - \\
\hline \multicolumn{3}{|l|}{ Yes } \\
\hline Suboptimal solid & $33(60)$ & $17(73.9)$ \\
\hline Liquid & $9(16.4)$ & $4(17.4)$ \\
\hline Hypocaloric liquid & - & $3(13)$ \\
\hline Starvation & $3(5.5)$ & - \\
\hline \multicolumn{3}{|l|}{ Gastrointestinal changes } \\
\hline No & $18(32.7)$ & $2(8.7)$ \\
\hline \multicolumn{3}{|l|}{ Yes } \\
\hline Nausea & $9(16.4)$ & $7(30.4)$ \\
\hline Vomit & $5(9.1)$ & $4(17.4)$ \\
\hline Diarrhea & $1(1.8)$ & - \\
\hline Anorexia & $31(56.4)$ & $18(78.3)$ \\
\hline \multicolumn{3}{|l|}{ Physical changes } \\
\hline No & $20(36.4)$ & - \\
\hline \multicolumn{3}{|l|}{ Yes } \\
\hline Muscle atrophy of arm & $14(25.5)$ & $20(87)$ \\
\hline Subcutaeous fat loss & $28(50.9)$ & $23(100)$ \\
\hline Foot edema & $9(16.4)$ & $5(21.7)$ \\
\hline Sacral edema & $1(1.8)$ & - \\
\hline Ascites & $5(9.1)$ & $3(13)$ \\
\hline \multicolumn{3}{|c|}{ Functional capacity limitation } \\
\hline Immobility & $19(34.5)$ & $12(52.2)$ \\
\hline
\end{tabular}

hypothalamus that is triggered by IL-1 may also cause anorexia. ${ }^{9}$ Decreased food intake can cause the body to undergo compensation to fulfill patients energy need. ${ }^{11}$

Increased release of cytokines and body compensation toward energy imbalance may cause muscle atrophy and subcutaneous fat loss. ${ }^{11}$ In this study, physical changes such as muscle atrophy of the arm and subcutaneous fat loss is more prevalent in severely malnourished patients (87\% and 100\%) compared to the mild to moderately malnourished patients 
(25.5\% and 50.9\%). A decrease in the average value of mid-upper arm muscle circumference (MAMC) and triceps skinfold (TSF) in mildly to moderately malnourished patients to severely malnourished patients might occured. ${ }^{6}$ Muscle atrophy and subcutaneous fat loss are signs of cancer cachexia. ${ }^{9}$ The diagnostic criteria for cachexia is weight loss more than $5 \%$ or more than $2 \%$ in patients with BMI less than $20 \mathrm{~kg} /$ $\mathrm{m} 2$. Patients in this study that met the weight loss criteria of cachexia are $50.9 \%$ in mildmoderate malnutrition and $87 \%$ in severe malnutrition.

About half of severely malnourished patients in this study is immobile (52.2\%) and this finding is not much of a difference to other study showing that immobile patients with cancer had severe malnutrition. ${ }^{13}$ The risk of malnutrition in hospitalized patients would increase when the patient is on bed rest. ${ }^{12}$ All patients with severe malnutrition in this study have experienced change of food intake. Most patients with mild-moderate malnutrition and severe malnutrition had suboptimal solid diet $(60 \%$ and $73.9 \%)$, suggesting that the majority of the patients are still able to eat but the intake is less than their nutritional needs. Therefore, it should be considered to give nutritional support to these patients. In general, oral nutritional supplement (ONS), enteral nutrition (EN), or parenteral nutrition (PN) according to their condition can be given. ${ }^{14}$ Mild to moderately malnourished and severely malnourished onco-hematological patients undergo antineoplastic therapy should be given ONS. When mucositis is present, then EN and ONS should be given to those with moderate mucositis; EN and PN should be given to severe mucositis. ${ }^{15}$

The limitation of the study is that this study only relying on a subjective nutritional assessment. A nutritional assessment should also be performed objectively, and thus, to have a comprehensive nutritional assessment. The SGA form is often missing in medical record, therefore, a good systematic nutritional assessment should be conducted accordingly.

To conclude, all NHL patients have experienced malnutrition assessed by a subjective global assessment with the majority had mild-moderate malnutrition; while most of severely malnourished patients have experienced change of food intake and loss of subcutaneous fat. A better macro and micronutrients for nutritional support scheme is crucial for NHL patients.

\section{References}

1. Reksodiputro AH, Irawan C. Limfoma nonhodgkin (LNH). In: Setiati S, Alwi I, Sudoyo AW, Simadibrata KM, Setiyohadi B, Syam AF, editors. Buku Ajar Ilmu Penyakit Dalam Jilid 3. 6th ed. Jakarta: Interna Publishing; 2014. p. 2977-93.

2. International Association of Cancer Registries, World Health Organization. Global cancer observatory: cancer today. Lyon, France: International Agency for Research on Cancer (IARC); 2018.

3. Planas M, Alvarez-Hernandez J, LeonSanz M, Celaya-Perz S, Araujo K, Harcia de Lorenzo. Prevalence of hospital malnutrition in cancer patients: a subanalysis of the PREDyCES® study. Support Care Cancer. 2016;24(1):429-35.

4. Hebuterne $X$, Lemarie $E$, Michallet $M$, Montreuil CBd, Schneider SM, Goldwasser F. Prevalence of malnutrition and current use of nutrition support in patients with cancer. JPEN J Parenter Enteral Nutr. 2014;38(2):196-204.

5. Correia MITD. Nutrition screening vs nutrition assessment: what's the difference? Nutr Clin Pract. 2017;33(1).

6. Wu B-W, Yin T, Cao W-X, Gu Z-D, Wang $\mathrm{X}$-J, Yan M, et al. Clinical application of subjective global assessment in Chinese patients with gastrointestinal cancer. World J Gastrointest Oncol. 2009;15(28):3542-9.

7. Siregar BM. Gambaran status nutrisi pada pasien kanker di Poli Penyakit Dalam Divisi Hemato-Onkologi Medik RSUP H. Adam Malik pada Bulan September-November 2014 [Minor Thesis]. Medan: Universitas Sumatera Utara; 2014.

8. Kumar N. Assessment of malnutrition and nutritional therapy approaches in cancer patients. In: Kumar N, editor. Nutritional management of cancer treatment effects. Berlin, Heidelberg: Springer; 2012. p. 7-41.

9. Aoyagi T, Terracina KP, Raza A, Matsubara $\mathrm{H}$, Takabe K. Cancer cachexia, mechanism and treatment. World J Gastrointest Oncol. 2015;7(4):17-29.

10. Silva FR, de Oliveira MG, Souza AS, Figueroa JN, Santos CS. Factors associated with malnutrition in hospitalized cancer patients: a croos-sectional study. Nutr J. 2015;14;123.

11. Aapro M, Arends J, Bozzetti F, Fearon K, Grunberg S, Herrstedt J, et al. Early recognition of malnutrition and cachexia in the cancer patient: a position paper of 
a European School of Oncology Task Force. Ann Oncol. 2014;25(8):1492-9.

12. Konturek PC, Herrmann HJ, Schink K, Neurath MF, Zopf Y. Malnutrition in Hospitals: It Was, Is Now, and Must Not Remain a Problem! Med Sci Monit. 2015;21:2969-75.

13. Nouh F, Omar M, Alshukri A, Younis M, Elmabsout A, Salem M, et al. Nutritional status of female breast cancer patients in Benghazi City of Libya. Sch J App Med Sci.
2017;5(6B):2179-87.

14. Arends J, Baracos V, Bertz H, Bozzetti F, Calder PC, Deutz NEP, et al. ESPEN expert group recommendations for action against cancer-related malnutrition. Clin Nutr. 2017(36):1187-96.

15. Gómez-Candela C, Albendea MAC, Milla SP, Arias RdP, Gómez JD, RodríguezDurán D, et al. Nutritional intervention in oncohematological patient. Nutr Hosp. 2012;27(3):669-80. 